\title{
A VISITA DE FRITZ HABER AO BRASIL
}

\author{
Cássius Klay Nascimento ${ }^{\mathrm{a}, \#}$ e João Pedro Braga ${ }^{\mathrm{b}, *,(1)}$ \\ a'Laboratório de Química, Escola Preparatória de Cadetes do Ar, 36205-058 Barbacena - MG, Brasil \\ ${ }^{\text {b} D e p a r t a m e n t o ~ d e ~ Q u i ́ m i c a, ~ U n i v e r s i d a d e ~ F e d e r a l ~ d e ~ M i n a s ~ G e r a i s, ~ 31270-901 ~ B e l o ~ H o r i z o n t e ~-~ M G, ~ B r a s i l ~}$
}

Recebido em 08/10/2020; aceito em 30/11/2020; publicado na web em 03/02/2021

FRITZ HABER VISIT TO BRAZIL. Fritz Haber was awarded with the Nobel Prize in Chemistry in 1918 for the ammonia synthesis from its gaseous components. This work was fundamental to stop starvation around the world. On the opposite, his engagement to produce chemical weapons during the First World War is also an important fact in the life of this scientist. This polemic scientist visited Brazil in 1923, carrying out a project to extract gold from the sea. The present work tries to recover the historical fact behind the visit of this scientist to Brazil.

Keywords: Fritz Haber in Brazil; chemical weapons; ammonia synthesis.

\section{INTRODUÇÃO}

Fritz Haber talvez seja um dos casos mais marcantes de quem na história da ciência pode ser amado e odiado ao mesmo tempo. ${ }^{1} \mathrm{O}$ cientista contribuiu para que os alimentos pudessem ser produzidos em grande escala para saciar a necessidade alimentar dos mais de 7.500 bilhões de humanos que moram em nosso planeta. Olhando a produção de alimentos, pode-se dizer que Haber foi um benfeitor da humanidade, mas ele também foi capaz de estar na linha de frente da produção de armas químicas, ${ }^{2}$ mostrando de forma clara seu lado terrivelmente desumano.

Fritz Haber nasceu em 9 de dezembro de 1868 na cidade de Breslau (hoje Wroclaw, Polônia), na época, a cidade pertencia à Prússia. Em 1904, sintetizou a amônia a partir do nitrogênio atmosférico de forma eficiente do ponto de vista energético e econômico, ${ }^{3}$ o primeiro marco na fabricação de fertilizantes nitrogenados e, portanto, na solução do problema da fertilização do solo. ${ }^{4}$ Seu processo foi aprimorado por Carl Bosch (1874-1940) e é chamado de "processo HaberBosch". Haber e Max Born (1882-1970) apresentaram o ciclo de Born-Haber como um método para avaliar a energia reticular de um sólido iônico. ${ }^{2}$ Elucidou a redução de nitrobenzeno em uma célula eletroquímica, em 1909, aperfeiçoou o eletrodo de vidro para medir o $\mathrm{pH}^{5}$ e publicou vários trabalhos revolucionários para pesquisa e ensino da termodinâmica (Figura 1). ${ }^{2}$

Haber tornou-se diretor do Instituto Kaiser Wilhelm de Química Física e Eletroquímica em 1911 (atualmente Sociedade Max Planck, em Berlim). Durante a Primeira Guerra Mundial centralizou a pesquisa e a produção alemã de armas químicas. O cientista foi laureado com o Prêmio Nobel de Química em $1918 .{ }^{6}$

No início da década de 1930 (Figura 2), Adolf Hitler (1889-1945) exigiu que judeus abandonassem todos os cargos ligados ao governo alemão. ${ }^{1}$ Haber, mesmo tendo origem judaica, seria poupado da medida por ser um herói de guerra, mas teria que demitir seus subordinados judeus. ${ }^{4}$ Haber não aceitou e afastou-se do governo. ${ }^{4}$ No dia 29 de janeiro de 1934, o cientista morreu na Basiléia, Suíça. ${ }^{3}$

Sua equipe desenvolveu também o Zyklon B (pesticida a base de ácido cianídrico, cloro e nitrogênio), empregado alguns anos depois de sua morte nos campos de extermínio nazistas da Segunda Guerra Mundial. $^{2}$

*e-mail: jpbraga@ufmg.br

\#e-mail alternativo: cassiuskn@ufmg.br

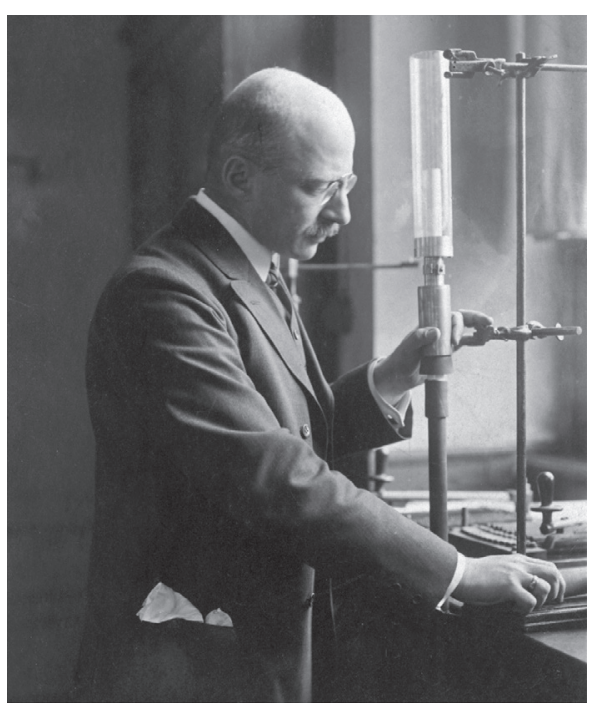

Figura 1. Fritz Haber em pé no laboratório fazendo um teste de chama, 1905. Fonte: Arquivos da Sociedade Max Planck, Berlim, Foto: I/3, autor desconhecido

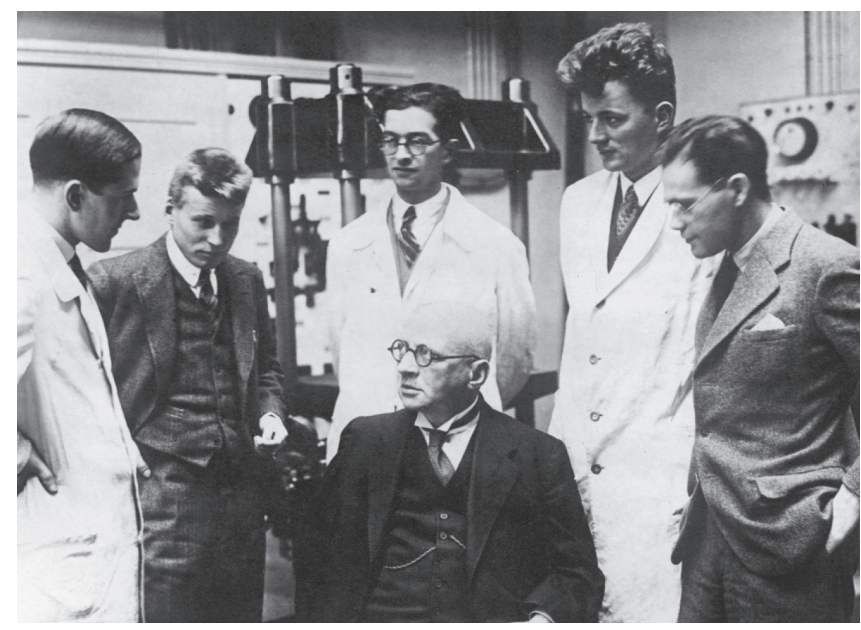

Figura 2. Haber sentado ao centro no Instituto Kaiser Wilhelm de Físico-Química e Eletroquímica, da esquerda para a direita: Eric Flint. v. Schweinitz, P. Goldfinger, Paul Harteck, Ladislaus Farkas, em 1930. Fonte: Arquivos da Sociedade Max Planck, Berlim/Foto: VIII.1/3, autor desconhecido 
O presente trabalho explora um aspecto não conhecido na história da química do Brasil: a presença desse polêmico cientista em nosso país. Apresenta o contato com jornalistas brasileiros, a explanação do seu pensamento científico para imprensa do Brasil e seu real interesse durante a visita ao hemisfério sul.

\section{POSIÇÃO CIENTÍFICA DE HABER}

Haber trabalhou em indústrias químicas, apesar de ter tido pouco destaque. Um desafio o lançou à fama: a solicitação de uma empresa austríaca para que ele buscasse o que muitos vinham tentando, mas não conseguiam, que era obter amônia a partir do nitrogênio presente no ar a baixo custo. O trabalho inicial não foi dos mais fáceis, pois, apesar da aparente simplicidade da reação, $\mathrm{N}_{2(\mathrm{~g})}+3 \mathrm{H}_{2(\mathrm{~g})} \rightarrow 2 \mathrm{NH}_{3(\mathrm{~g})}$, mas a quantidade de calor necessária para fazer com que a reação tenha um rendimento aceitável comercialmente é muito grande e a energia usada pode levar a degradação da amônia formada. Os primeiros resultados obtidos por Haber não foram os mais animadores. Provavelmente o cientista não iria dispender mais energias sobre o seu trabalho, mas um fator foi determinante para que ele continuasse a trabalhar e enfim obtivesse sucesso. Seus resultados foram ridicularizados pelo já famoso e importante cientista Walther Hermann Nernst (1864-1941), responsável por formular a Terceira Lei da Termodinâmica. ${ }^{7,8}$ Haber aumentou seus esforços e, com o apoio de pessoas como o engenheiro Robert Le Rossignol (1884-1976) e Carl Bosch, conseguiu obter sucesso na produção da amônia. Sua patente foi questionada na justiça, mas, no dia 4 de março de 1912 teve seu direito reconhecido. ${ }^{4}$

Programas de controle de natalidade, como a política do filho único implementada na década de 1970 na China, ${ }^{9}$ foram suportados principalmente pelas teorias neomalthusianas, que estão estruturadas, em parte, no trabalho de Thomas Malthus (1736-1834), Ensaio Geral sobre a População. Com o Trabalho de Malthus obteve-se a célebre afirmação: “ A população quando não controlada cresce em razão geométrica, mas os recursos de subsistência crescem em razão aritmética". ${ }^{10}$ Os programas de controle aplicados em nosso tempo talvez poderiam ter sido muito mais rígidos, não fosse o trabalho de Fritz Haber, que visava a produção de amônia a partir do nitrogênio do ar. ${ }^{2}$

O nitrogênio é um dos principais macronutrientes para as plantas e é responsável pelo seu crescimento e pela coloração verde-escura das folhas. Atua no desenvolvimento do sistema radicular, na fotossíntese e é parte constituinte da clorofila, vitaminas, carboidratos e proteínas. ${ }^{1}$ A maioria dos seres vivos precisam de nitrogênio para manter a vida. Deve-se lembrar que apesar do ar na Terra ser muito rico em nitrogênio, algo em torno de $78 \%$, os seres que aqui habitam não possuem a capacidade de absorvê-lo na forma de gás nitrogênio, $\mathrm{N}_{2}$, forma na qual está disponível na troposfera. São fontes mais comuns de nitrogênio mineral para as plantas superiores o nitrato $\left(\mathrm{NO}_{3}^{-}\right)$e o amônio $\left(\mathrm{NH}_{4}^{+}\right)$. O nitrogênio atmosférico é usado apenas por plantas que vivem em simbiose com bactérias fixadoras de $\mathrm{N}_{2}$. Haber facilitou o obtenção do nitrogênio do ar e sua transformação em formas mais acessíveis às plantas. ${ }^{1}$

A atuação de Marie Sklodowska Curie e Fritz Haber durante a Primeira Guerra Mundial é um exemplo de como a ciência pode contribuir com a humanidade, ${ }^{11}$ pois tudo depende de como os conhecimentos científicos são usados. ${ }^{12}$ Marie Curie ajudava sua pátria adotiva, a França, com seus conhecimentos sobre radiações, por exemplo na criação dos famosos petites Curies, ambulâncias radiológicas que eram usadas no atendimento aos soldados feridos. A cientista esteve inclusive nas frentes de batalha, realizando radiografias com equipamentos montados nos veículos, fornecendo auxílio fundamental ao trabalho dos médicos e ajudando a salvar vidas humanas. ${ }^{13}$
Mas também, era possível ver, durante a mesma guerra, a ciência sendo usada da pior forma possível. Em 22 de abril de 1915, um exemplo marcante acontece na cidade de Ypres na Bélgica, onde alguns soldados franceses em suas trincheiras começaram a vomitar, tendo dificuldades para respirar e sofrendo queimaduras. Percebia-se que uma nuvem esverdeada estava sobre a região. Algo em torno de 5.000 soldados franceses foram asfixiados. ${ }^{2}$ Apesar da Convenção de Haia, 1899, ter proibido o uso de Armas químicas, em Ypres ocorreu o primeiro uso em larga escala dessa arma de guerra, de forma que os soldados morreram em alguns minutos. Os alemães tinham acabado de liberar aproximadamente 170 toneladas de gás cloro no ar. Era o começo da guerra química na chamada Frente Ocidental da Primeira Grande Guerra. Quem estava na linha de frente ajudando os comandantes militares a obter sucesso na maléfica empreitada era ninguém menos que Fritz Haber. O "sucesso" da ação fez com que o cientista recebesse a patente de capitão do exército. ${ }^{4}$

Sua primeira esposa, Clara Immerwahr (1870-1915), primeira mulher a obter o título de doutorado em química na Alemanha, não comungava do pensamento de Haber em relação às armas químicas. O sofrimento abalou de tal forma Clara que, em 2 de maio de 1915, ela foi encontrada morta pelo filho do casal. Provavelmente, ela não conseguiu manter o equilíbrio diante do pensamento e ações odiosas de Haber e se suicidou. ${ }^{2}$ Mas alguns aspectos, do período próximo à morte de Clara Immerwahr, não podem ser ignorados, pois ela apresentava forte depressão, tinha uma vida pessoal insatisfatória e não se ocupava profissionalmente. As atividades de Haber não foram as únicas causas da atitude trágica de sua esposa. ${ }^{14,15}$ Após o término da Guerra, o cientista teve que fugir para a Suíça, pois era considerado criminoso de guerra pela Tríplice Entente (Reino Unido, França e Rússia). Voltou para a Alemanha tempos depois, após ser perdoado. Haber foi laureado com o Prêmio Nobel de química em 1918 pelo desenvolvimento de um processo, comercialmente viável, para a síntese da amônia. Recebeu o prêmio em 1920 sob protestos de vários membros da comunidade científica, devido ao seu mal uso da ciência durante a guerra.

\section{ENCONTRO DE FRITZ HABER COM UM JORNALISTA BRASILEIRO}

Com o final da Primeira Guerra e a derrota da Alemanha, o país foi obrigado pagar as indenizações definidas no Tratado de Versalhes, assinado em 1919. O governo alemão teve que arcar com compensações com o valor inicial de 269 bilhões de marcos, que foram acrescidos de outras taxas. No conflito morreram dez milhões de soldados, mas a dívida foi totalmente quitada somente 92 anos depois, em 2010, com a última parcela no valor de 70 milhões de euros. ${ }^{1}$

Poucos anos após o fim da guerra, o ufanismo de Haber o levou a buscar novas fontes de recursos para que a Alemanha conseguisse pagar a dívida contraída após o armistício.

As preocupações do pesquisador o conduziram a buscar uma forma retirar o ouro dissolvido nas águas dos mares. ${ }^{16}$ Quando recebeu o Prêmio Nobel em Estocolmo, o cientista visitou Svante August Arrhenius (1859-1927), que o incentivou com dados de pesquisas à busca de um método para retirar o ouro do mar. ${ }^{17}$ Para Arrhenius, a natureza já havia feito a parte exploratória, agora seria só coletar o metal, o que produziria um lucro considerável para a economia alemã. ${ }^{6}$ Haber realizou uma pesquisa muito completa sobre a retirada de ouro das águas oceânicas. Seu pensamento era de que, obtendo um método eficiente, conseguiria extrair tanto ouro dos mares que seria possível pagar a dívida de guerra da Alemanha. ${ }^{18}$

Seu magnífico sonho o levou a uma jornada incansável a bordo do Navio de pesquisa Meteor. O trabalho ganhou mais força a partir de 1924, mas terminou antes do fim da década de 1920, uma vez que a quantidade de ouro que se conseguia obter não era suficiente para 
pagar os custos da extração. Em termos econômicos e práticos, não se justificaria obter ouro por esse caminho. ${ }^{18}$

Após examinar amostras obtidas, tanto pelo Meteor quanto pelos navios dinamarqueses Dara e Goodthaab, concluiu-se que a concentração de ouro nas regiões ártica e antártica era maior que nas regiões equatoriais. ${ }^{19}$ Pelo seu trabalho, afirmou também que o ouro era encontrado em menor concentração no atlântico sul. Nas águas próximas aos polos da Terra, era possível obter de quatro a cinco vezes mais ouro, mas, mesmo assim era inviável economicamente. Haber conclui que havia a possibilidade de encontrar ouro em concentrações bem maiores em alguns locais do oceano, mas isso seria como que procurar uma agulha no palheiro. ${ }^{18}$

Fritz Haber fazia parte da der Notgemeinschaft Deutschen Wissenschaft (Associação de Emergência da Ciência Alemã) ou NG, que foi fundada em 30 de outubro de 1920. A NG foi uma iniciativa dos principais membros da Preußische Akademie der Wissenschaften (Academia de Ciências da Prússia, PATA) - Fritz Haber, Max Planck (1858-1947), Ernst von Harnack (1888-1945) e Friedrich SchmidtOtt (1860-1956). A associação tinha o objetivo inicial de aliviar especialmente o aumento das necessidades financeiras após a I Guerra Mundial, devido à inflação monetária e custos geralmente mais elevados das pesquisas científicas.

No dia 18 de dezembro de 1920 o jornal Correio da Manhã entrevistou Haber ${ }^{20} \mathrm{O}$ correspondente internacional foi Francisco de Assis Chateaubriand Bandeira de Melo (1892-1968), fundador dos Diários Associados em 1924, conglomerado que reuniu dezenas de jornais, revistas e estações de rádio, ele também foi o responsável por trazer a televisão para o Brasil ao criar a TV Tupi em 1950. Chateaubriand esteve com Haber em seu laboratório no KaiserWilhelm-Institute, local que foi visitado por diversas personalidades da ciência como Albert Einstein (Figura 3).

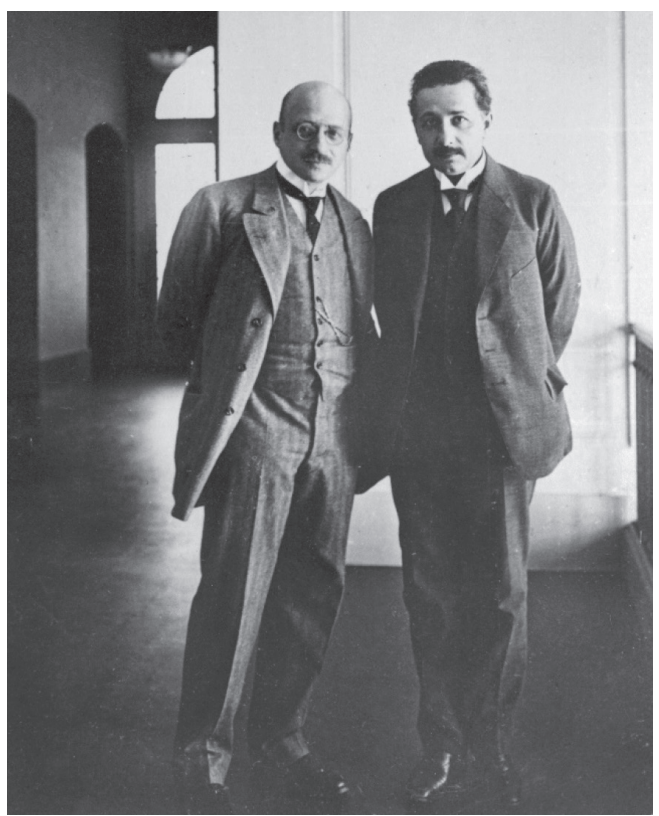

Figura 3. Encontro com Albert Einstein (1879-155) no Instituto Kaiser Wilhelm de Físico-Química e Eletroquímica, Berlim, em 1 de julho de 1914. Fonte: Arquivos da Sociedade Max Planck, Berlim/Foto: VI/2, Setsuro Tamaru

O jornalista iniciou a reportagem com o título e alguns destaques, como se segue:

\section{AS CONDIÇÕES DA SCIENCIA ALLEMÃ}

Haber, o famoso chimico que descobriu a formula do azotosynthetico, fala ao "Correio da Manhã"
Se o espírito inventivo da Europa não se mantiver de pé, creando sempre, assistiremos a decadência da civilização do velho mundo.

Haber falou dos seus principais trabalhos, destacando principalmente a produção da amônia por meio do nitrogênio do ar. De forma muito cordial, demonstrou que o Brasil não era um país desconhecido para ele. Falou que a Alemanha estava pronta para atender as necessidades do Brasil em termos de anilina. Interessava, também, pela borracha natural, considerando que, na década de 1920 , a borracha natural era mais fácil de entrar nos mercados do que a artificial devido ao baixo preço que estava sendo praticado. Outra vantagem que ele destacava era que a borracha natural era ainda mais elástica que a artificial naquela época.

“ - A minha impressão disse-me Haber, é que a borracha artificial não dá grande esperança de uma concorrencia victoriosa ao similar natural, principalmente depois que se accentuou nos mercados a baixa do preço deste, pelo apparecimento da hevea (seringueira) asiática e africana, em vasta quantidade. A elasticidade do produto artificial é sempre menor que a da natural, pois que a qualidade daquelle não é a mesma desta.

Depois falou que, mesmo sem condições científicas, não abandonava o Kaiser-Wilhelm-Institute. Referiu-se às grandes dificuldades pelas quais passava a Alemanha e que não concordava com punições tão pesadas. A seguir é apresentado um pequeno trecho das palavras melancólicas, segundo o jornalista, do cientista:

- Esta é a paz de direito e de justiça que os estados portabandeiras da civilização nos deram. Ella tanto despedaça a Allemanha como a Europa, e elimina toda a possibilidade de reconstrucção continental. Não podemos viver sob esta atmosphera de desconfiança e na idéa de que uma nação deve pagar os erros de todas.

Assis Chateaubriand se comprometeu, em voltando para o seu país, defender que algumas pessoas do Brasil ajudassem a fortalecer a ciência germânica, que, para o jornalista, era a flor mais robusta da humanidade, e que até aquele momento tinha contribuído muito para a grandeza e perfeição do espírito humano. Haber gostou muito da promessa feita pelo brasileiro e respondeu que "os verdadeiros amigos são os que chegam na hora do infortúnio". Mostrou que estava feliz que os seus compatriotas residentes no Brasil pudessem ajudar a ciência alemã, e disse que os cientistas alemães saberiam mostrar-se dignos da confiança depositada nas atividades e no amor ao trabalho que eles tinham.

- Os verdadeiros amigos são os que nos chegam nas horas do infortunio. Espero esse concurso da intelligencia brasileira, dos meus compatriotas, residentes na sua terra, como uma dadiva reproductiva, em benefício mesmo da colectividade humana. Os homens de sciencia allemães, mostrar-se pelo seu esforço, dignos da confiança de grande povo de alem mar, na nossa actividade e no nosso amor ao trabalho.

O jornalista disse que o amor e a fé na ciência não morriam no coração dos sábios alemães, mesmo faltando muitas vezes até o que comer. Chateaubriand terminou sua matéria clamando "Exorto a cultura brasileira a escrever uma das páginas mais puras da sua história, ajudando a salvar a cultura germânica, a qual tanto devemos, da catástrofe que a ameaça." ${ }^{20}$ 


\section{HABER NO RIO DE JANEIRO}

Devido à busca pelo ouro das águas dos mares e à necessidade de arrecadar fundos para as pesquisas, Haber foi a Buenos Aires, a fim de tentar obter mais recursos financeiros de empresários alemães que residiam na Argentina. Nessa viagem, ele proferiu, no Clube Alemão em Buenos Aires, uma palestra altamente patriótica sobre o tema da química alemã nos últimos dez anos. ${ }^{2}$

Baseado em reportagem do jornal Correio da Manhã do Rio de Janeiro em 8 de novembro de 1923, Haber chegou no Brasil a bordo no navio Wurttemberg ${ }^{21}$ (afundado em 1940, no início da Segunda Guerra, por contratorpedeiros britânicos na cidade portuária de Narvik na Noruega).

O mesmo jornalista disse que, depois de visitar a Argentina e Uruguai, o cientista ficaria um tempo no Brasil, quando do seu retorno à Europa. ${ }^{21}$

A sua viagem à América do Sul não é propriamente de recreio, pois elle vem tambem com o interesse de estudar vários problemas que dizem respeito à chimica, e conhecer $o$ adeantamento das nações sul-americanas, tanto assim que irá primeiro a Buenos Aires, não sabendo o tempo que permanecerá na Argentina, indo depois ao Uruguay e de volta ficará algum tempo no Rio, onde tem vários amigos. ${ }^{21}$

Fritz Haber foi recebido no Brasil como o sábio alemão que conseguiu fazer uma reação que levaria à produção de explosivos sem a necessidade do salitre das minerações. Não há citação de que o método de obtenção da amônia a partir o nitrogênio do ar aumentaria a produção de alimentos. ${ }^{21}$

Foi justamente nesse momento que o professor Fritz, depois de continuados estudos e inumeras experiências, num acto de abnegação pela pátria, que via em perigo, descobre o processo que consiste em obter o salitre existente no ar, na atmosphera, para applica-lo no fabrico da polvora negra. ${ }^{21}$

Descreve-se que o cientista despertava a atenção pelas descobertas que fazia, no seu incansável trabalho em laboratórios. Devido aos seus inúmeros trabalhos científicos "patrióticos", o povo alemão o admirava e respeitava muito. Após a guerra, sua fama se espalhou por todos os continentes, inclusive sendo bem conhecido em países da América do Sul, como Brasil e Argentina.

O encontro com o jornalista foi na parte mais alta do Wurttemberg, o cientista estava apressado, pois permaneceria pouco tempo na cidade do Rio de Janeiro (Figura 4). A conversa foi rápida, mas o "professor Fritz", como foi chamado, recebeu com um sorriso e cordialidade, demonstrando não estar incomodado. Mostrou-se ser uma figura extremamente simpática e muito modesto, diferente de Nernst, que era considerado um pouco arrogante. ${ }^{1}$ Não quis direcionar muito sua fala para seus feitos e nem para seu nome dentro da ciência mundial, mas preferiu dedicar-se mais a elogiar as belezas do Rio. Disse que ansiava por passear e conhecer, aproveitando as horas nas quais o navio estaria atracado no porto, a Bahia da Guanabara, a qual para ele era a mais bela do mundo e lhe proporcionou à vista encantos nunca vistos, nem tampouco sonhados. ${ }^{21}$

Haber disse, quando no Brasil, que no pós-guerra o povo alemão queria simplesmente paz e ordem. O cientista minimizava o problema que seria para o mundo ter, naqueles tempos, uma Alemanha forte, principalmente em termos bélicos. Pensava que as punições que os vencedores haviam imposto sobre seu país eram devidas a alguns poucos maus elementos que eram imbuídos de ideias subversivas. Para ele, essas pessoas, que não tinham consciência do que falavam

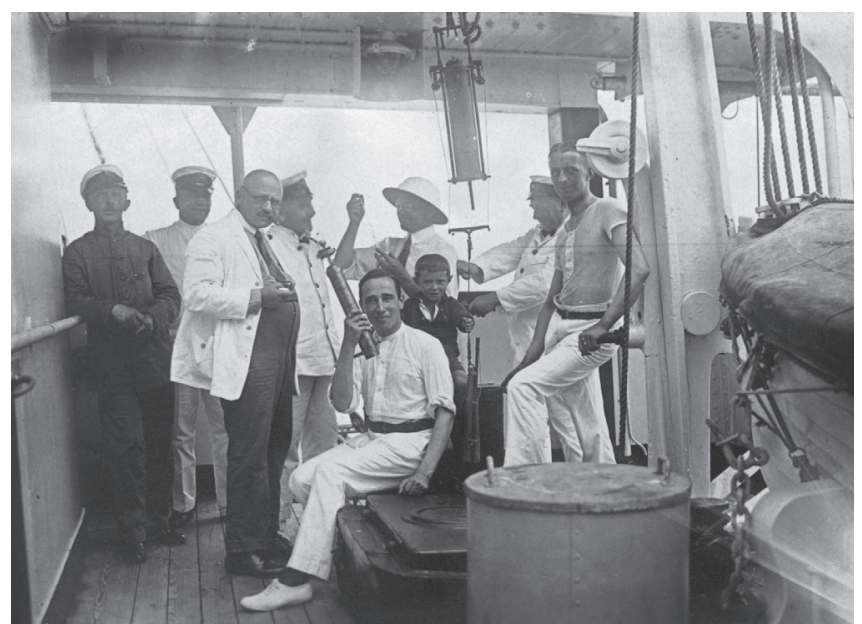

Figura 4. Expedição "Ouro na água do Mar", Haber, em pé, a bordo do navio com destino ao Brasil, sentado: G. Lehrcke, atrás com um capacete: Hans Eisner e na extrema direita: Fritz Matthias, 1923. Fonte: Arquivos da Sociedade Max Planck, Berlim/ Foto: X/2, autor desconhecido

e faziam, estavam sendo orientadas por alguns ideólogos, cujo desejo único era pisar ainda mais na Alemanha, que já se encontrava humilhada perante o mundo. Dizia o cientista que essa gente estava cheia de receio de que ela pudesse reaver suas forças perdidas e ganhar seu prestígio anterior entre as grandes nações do mundo. A história mostrou que Haber estava errado: a retomada do poderio alemão levou o mundo à Segunda Grande Guerra, com graves consequências, inclusive, para o próprio cientista. ${ }^{21}$

Após a conversa, o professor Fritz foi ao encontro de amigos que foram buscá-lo no navio, saindo para o seu tão esperado passeio. Não foi citado quem eram os amigos, mas Haber e a NG procuravam alemães que viviam fora do país que tivessem uma boa condição financeira para ajudar a financiar pesquisas científica na Alemanha. No caso de Haber, principalmente a busca por uma forma eficiente de obter ouro das águas dos mares.

O Jornal O Paiz de 8 de novembro de 1923 diz que o Wurttemberg entrou na Bahia da Guanabara em torno das 7 horas da manhã, sendo o navio inspecionado e liberado a seguir. ${ }^{22}$

Um paquete novo, construído recentemente em estaleiros allemães, ancorou, hontem, pela manhã, em nosso porto -o Wüttemberg - que acaba de ser incorporado à frota mercante da Hamburg Amerika Linie.

$O$ referido paquete transpoz a barra pouco depois das 7 horas e permaneceu pouco tempo no ancoradouro de navios mercantes, por isso que o médico da Saude, tendo verificado, rapidamente, serem excellentes as condições sanitárias de bordo, permitil que o grande e confortavel transatlantico fosse atracar no armazem 18, o que se verificou pouco depois.

O jornalista encontrou Haber no último piso e, sentado em uma cadeira confortável no local, conversaram sobre os principais trabalhos do cientista. Após, Haber deu sua opinião sobre alguns temas pelos quais o mundo estava vivendo. Falou que naqueles anos pós-final da Primeira Guerra, infelizmente a paz a qual as nações estavam vivendo não estava apoiada sobre alicerces sólidos e estáveis. Disse que uma atmosfera de ódio, rancor e ambição ficava abafada, mas, em alguns momentos, explodia. Por isso, ninguém sabia como seria o futuro.

- Infelizmente as nações ainda não vivem uma paz assente em alicerces sólidos e estaveis. Os povos estão ainda sob 
uma atmosphera de odios, ramcores e ambições, que cessam aqui, para explodir além, tornando a vida insupportavel, por isso que ninguem sabe ao certo que será o dia de amanhã.

Para ele, existia um interesse de muitos pela paz, sem a qual não há como existir desenvolvimento algum. Sob seu ponto de vista, a ciência era a mais prejudicada pela situação em que o mundo vivia, e tinha sido de tal forma prejudicada, que o progresso da humanidade estava paralisado, talvez retroagido vários anos. Ainda falou que para se ter uma vida digna a estabilidade política e econômica de um país é fundamental.

"A sciencia é a maior victima da situação.

“ Ella tem sido sacrificada em extremo, pois não se comprehende seculo como o que atravessamos se note uma paralysação em tudo o que diz respeito ao progresso. Creio mesmo que retrogradamos talvez cem anos...

O periódico $O$ Paiz apresenta, também, que ele desembarcou e foi fazer alguns passeios pelo Rio. Depois seguiria para Buenos Aires para trocar ideias sobre assuntos científicos com colegas argentinos (Figura 5).22

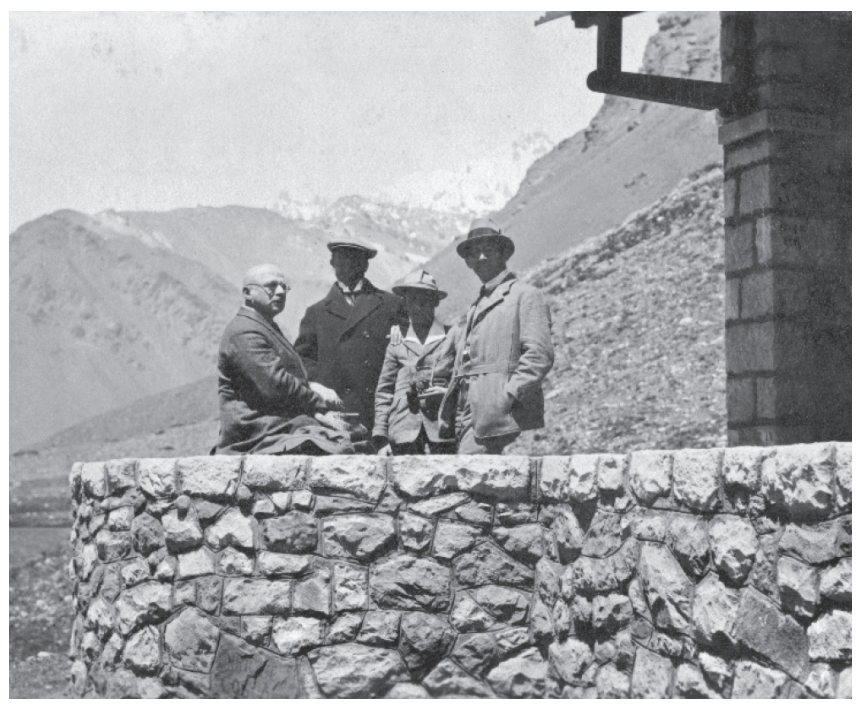

Figura 5. Excursão ao Andes por ocasião da expedição ouro em água do mar, Fritz. Haber sentado à esquerda, 27 de novembro de 1923. Fonte: Arquivos da Sociedade Max Planck, Berlim/Foto: X/30, autor desconhecido

\section{DEFESA CONTRA AS ARMAS QUÍMICAS}

Algo interessante, parece que Haber após ter contribuído para a morte de vários militares e civis com a produção e orientação quanto ao uso de armas químicas durante a Primeira Guerra, havia mudado sua opinião já em 1926. Numa reportagem do Jornal Diário de Pernambuco de 27 de julho de 1926, falou-se que Haber fez uma palestra na qual descreveu os horrores da guerra química dizendo que muitas crianças e adultos inocentes poderiam ser vítimas. Descreve o jornal:

O emprego de gases venenosos como arma de guerra continua a preocupar os scientistas. Ainda agora em Berlim, $o$ professor Fritz Haber, uma das personalidades mais cotadas da sciencia alleman o inventor do nitrogenio synthetico, fez. uma conferencia descrevendo os horrores dos ataques com gaz asphyxiante numa guerra futura com suas possíveis victimas innocentes, que serão as mulheres e as crianças.
Avaliou que as substâncias nocivas foram muito eficientes como armas de guerra, mas, em muitos lugares, haviam exagerado, aumentando os graves efeitos e ainda causando pânico. Explicou como funcionam as armas e como se fazia para que seus efeitos não fossem anulados. Falou também que era contra o uso das armas químicas e que a Alemanha, enquanto país, receberia muito bem a proibição.

O orador disse ainda que a proibição de utilisar gazes asphyxiantes em caso de guerra seria muito bem recebida na Allemanha, primeiro por um nobre sentimento de humanidade e depois porque a Allemanha neste ramo scientífico e militar não acompanhou o desenvolvimento de outros paizes.

Haber terminou a conferência afirmando, também, que todos deveriam se unir para evitar a morte de mais inocentes. ${ }^{23}$ As palavras do cientista foram registradas pelo Diário de Pernambuco:

"Nós todos devemos nos unir para abolir esse processo que, mais do que contra os exercitos, se faz sentir contra innocentes, as mulheres e as crianças."

\section{COMENTÁRIOS FINAIS}

Segurança alimentar e militar para a Alemanha eram os objetivos-chave iniciais para Haber. Após a Primeira Grande Guerra, acrescentou-se a tentativa de salvar o país da profunda crise econômica. ${ }^{24}$

Fritz Haber esteve no Brasil em busca do ouro presente nas águas dos oceanos, o que salvaria a Alemanha de suas dificuldades financeiras impostas por dívidas de guerra. Em termos econômicos, o projeto não teve sucesso, mas, cientificamente, foi fundamental para o desenvolvimento de novas técnicas analíticas para obtenção de ouro e outros metais.

O cientista, durante sua estada no Brasil, expôs seu pensamento sobre vários temas científicos relacionados com a química, deixando a forte impressão de que não era mais um defensor da utilização de armas químicas, algo fundamental para corrigir os caminhos seguidos por este importante pesquisador. $\mathrm{Na}$ sua empreitada patriótica para salvar a Alemanha das dificuldades financeiras, utilizou-se do exemplo de como a ciência pode ser influenciada pelas demandas econômicas da sociedade na qual ela se desenvolve. Para isso, contava inclusive com a ajuda de brasileiros simpáticos à sua causa e dos alemães e descendente que residiam em nosso país. O conhecido jornalista e empresário Assis Francisco de Assis Chateaubriand Bandeira de Mello, o Chatô, foi uma das pessoas que engajaram na busca de apoio a empreitada do cientista. $\mathrm{O}$ fato foi apresentado em matéria do jornal Correio da Manhã, a 18 de dezembro de 1920, pelo próprio jornalista, que na época era correspondente internacional.

Com o pesquisador no Brasil, a imprensa destacou sua importância na obtenção de derivados da amônia principalmente para uso bélico, provavelmente devido à proximidade com final da guerra, pois o assunto estava muito vivo na mente de todos.

Haber se mostrou muito educado e afável no Brasil, elogiou as belezas da capital federal na época e deixou clara sua vontade de conhecer as belezas do Rio de Janeiro.

Alguns anos após sua vinda à América do Sul, Haber fez questão de afirmar que era contra as armas químicas, uma inflexão, visto que, num passado recente, ele muito havia contribuído, de forma marcante, para a produção e uso contra os militares e a população civil. 


\section{AGRADECIMENTOS}

Os autores gostariam de agradecer ao CNPq e à CAPES pela ajuda financeira. À Susanne Uebele da Sociedade Max Plank BerlimDahlem, por ter cedido as fotografias de Fritz Haber. Agradecemos ao Prof. Dr. Carlos A. L. Filgueiras pelas constantes discussões sobre a história da química no Brasil.

\section{REFERENCIAS}

1. Kean, S.; O último suspiro de César: A história épica do ar à nossa volta. Zahar: Rio de Janeiro, 2019.

2. Stoltzenberg, D.; Fritz Haber: Chemist, Laureat, German, Jew, Chemical Heritage Foundation: Pensilvânia, 2005.

3. Berl, E.; J. Chem. Educ. 1937, 14, 203.

4. Chagas, A. P.; Quim. Nova 2007, 130.

5. Fernandes, J. C. B.; Kubota, L. T.; Oliveira Neto, G.; Quim. Nova 2001, 24, 120.

6. Jaenicke, J.; Naturwissenschaffen 1935, 23, 57.

7. Nascimento, C. K.; Braga, J. P.; Quim. Nova 2019, 42, 361.

8. Braga, J. P.; Físico-química: Aspectos Moleculares e Fenomenológicos, Ed. UFV: Viçosa, 2002.
9. Howden, D.; Zhou, Y.; Econ. Aff. 2014, 34, 353.

10. Malthus, T. R.; An Essay on the Principle of Population, J. Johnson: Londres, 1798.

11. Nascimento, C. K.; Braga, J. P.; Nature 2017, 551, 440.

12. Nascimento, C. K.; Braga, J. P.; Quim. Nova 2011, 34, 1888.

13. Braga, J. P.; Nascimento, C. K.; A Visita de Marie Curie ao Brasil, Livraria da Física: São Paulo, 2017.

14. Friedrich, B.; Hoffmann, D. Em One Hundred Years of Chemical Warfare: Research, Deployment, Consequences; Friedrich, B., Hoffmann, D., Renn, J., Schmaltz, F., Wolf, M., eds.; Springer: Cham, 2017, cap. 1.

15. Dunikowska, M.; Turko, L.; Angew. Chem. Int. Ed. 2011, 50, 10050. Title: Fritz Haber: The Damned Scientist

16. Diário de Pernambuco, 1924, 297, 7.

17. Putnam, G. L.; J. Chem. Educ. 1953, 30, 576.

18. Carson, R.; O mar que nos cerca, Gaia: São Paulo, 2010.

19. Correio da Manhã, 1926, $9657,10$.

20. Correio da Manhã, 1920, 7962, 1.

21. Correio da Manhã, 1923, $9909,1$.

22. O Paiz, 1923, 14263, 4.

23. Diário de Pernambuco, 1926, 170, 3.

24. Erisman, J. W.; Sutton, M. A; Galloway, J.; Klimont, Z; Winiwarter, W.; Nature 2008, 1, 636. 